\title{
Pre-operative evaluation of lung function test results
}

\section{To the Editors:}

The European Respiratory Society/European Society of Thoracic Surgeons joint clinical guidelines on fitness for radical therapy in lung cancer patients (surgery and chemoradiotherapy) were published in the July 2009 issue of the European Respiratory Journal [1]. This comprehensive and very important document provides guidelines for the risk evaluation of candidates for lung cancer surgery. We fully agree that the lung function variables forced expiratory volume in $1 \mathrm{~s}$ (FEV1) and diffusing capacity of the lung for carbon monoxide $(D \mathrm{~L}, \mathrm{CO})$, together with exercise capacity, are essential components in the risk stratification. We do not, however, agree on the recommended interpretation and evaluation of the test results. In the guidelines, lung function results are evaluated as customary in terms of percent of predicted normal values, i.e. corrected for sex, age, height and, for some variables, also weight (exercise test) [1]. In our opinion, the correction for age is inappropriate when estimating peri-operative risk. This is because expressing lung function results in percent of predicted normal values results in ignorance of the normal age-related decline in lung function and exercise capacity. The guidelines recommend a post-operative predicted FEV1 value of $30 \%$ predicted to be a high-risk threshold. $30 \%$ pred normal FEV1 for a 70-yr-old male with a height of $178 \mathrm{~cm}$ is $0.9 \mathrm{~L}$ compared with $1.3 \mathrm{~L}$ for a male of the same height aged $25 \mathrm{yrs}$ [2]. Thus, according to the recommendations, the high-risk threshold regarding FEV1 is $0.9 \mathrm{~L}$ for a 70 -yr-old patient but $1.3 \mathrm{~L}$ for the $25 \mathrm{yr}$ old! There are of course similar consequences regarding $D \mathrm{~L}, \mathrm{CO}$ and exercise capacity.

One of several possible ways to deal with this problem is to express results of lung function tests and exercise tests of adults as percent of predicted normal at age $25 \mathrm{yrs}$ (\% pred25yrs) irrespective of the actual age. In the example above regarding the 70-yr-old patient, the guideline recommended high-risk threshold of post-operative predicted $30 \%$ pred corresponds to $0.9 \mathrm{~L}$, which is equivalent to a post-operative predicted value of $\sim 20 \%$ pred25yrs. Thus, we suggest the high-risk threshold to be $20 \%$ pred25yrs for FEV1, DL,CO and exercise capacity.

\section{B. Houltz, J. Olofson and B. Bake}

Dept of Lung Medicine and Allergology, Sahlgrenska University Hospital, Gothenburg, Sweden.

Correspondence: B. Houltz, Dept of Lung Medicine and Allergology, Sahlgrenska University Hospital; Gothenburg, S-413 45, Sweden. E-mail: birgitta.houltz@medfak.gu.se

Statement of Interest: None declared.

\section{REFERENCES}

1 Brunelli A, Charloux A, Bolliger CT, et al. ERS/ESTS clinical guidelines on fitness for radical therapy in lung cancer patients (surgery and chemo-radiotherapy). Eur Respir J 2009; 34: 17-41.
2 Quanjer PH, Tammeling GJ, Cotes JE, et al. Lung volumes and forced ventilatory flows. Report Working Party Standardization of Lung Function Tests, European Community for Steel and Coal. Official Statement of the European Respiratory Society. Eur Respir J 1993; 6: Suppl. 16, 5-40.

DOI: $10.1183 / 09031936.00170309$

\section{From the authors:}

We read with interest the correspondence by B. Houltz and coworkers in which they comment on the recently suggested update of an algorithm for the functional assessment before lung resection, which forms part of the European Respiratory Society (ERS)/European Society of Thoracic Surgeons (ESTS) clinical guidelines on fitness for radical therapy in lung cancer patients (surgery and chemo-radiotherapy [1]. This algorithm, originally proposed in 1998 [2], is based on four key parameters: 1) a cardiac evaluation according to time-honoured principles well-known in the cardiology literature (ECG, stress ECG, etc.); 2) a pulmonary evaluation with assessment of pulmonary mechanics using spirometry (forced expiratory volume in $1 \mathrm{~s}$; FEV1); 3) a pulmonary evaluation with assessment of gas exchange using the diffusing capacity of the lung for carbon monoxide (DL,CO); and 4) for patients who do not qualify/disqualify for a given amount of resection after these initial tests, a combined cardio-pulmonary exercise test with the determination of peak oxygen uptake $\left(V^{\prime} \mathrm{O}_{2}\right.$,peak) is proposed. While B. Houltz and co-workers agree with all parameters used in the algorithm, they query the use of percent of predicted values for the variable age, while not contesting them for sex, height and weight. They argue that correction for age is inappropriate as the normal age-related decline in lung function and exercise capacity is ignored. Interestingly, we do not ignore this decline; on the contrary, this decline is used in order not to rule out older people from resections simply because their absolute values for a given parameter have declined. To use the example given by $\mathrm{B}$. Houltz and co-workers: the new lowest cut-off for safe resection of pulmonary tissue proposed by the ERS/ESTS Task Force is 30\% post-operative predicted (ppo) for FEV1 and $D \mathrm{~L}, \mathrm{CO}$, which for the 70-yr-old male would amount to $0.9 \mathrm{~L}$ for FEV1 [3]. If this male was aged 25 yrs 0.9 L would only be $20 \%$ of predicted, therefore, B. Houtlz and co-workers argue that $20 \%$ ppo adjusted for 25 yrs be used for all ages for FEV1, and also for $D \mathrm{~L}, \mathrm{CO}$ and $V^{\prime} \mathrm{O}_{2}$,peak.

This suggestion implies that irrespective of age one needs a certain absolute value and, therefore, younger people could have a lower functional reserve when expressed in predicted values. Although this suggestion sounds interesting, we would definitely like to caution against its use. First, we are not aware of any published data supporting this view and secondly lowering the ppo values for FEV1 and DL,CO from the original $40 \%$ suggested in 1998 [2] to $30 \%$ [1] is a major step and needs prospective validation in larger studies. The suggested lowering of this cut-off value to $20 \%$ adjusted for 25 yrs of age may 
well put young people at an unacceptable risk. A young person most likely needs higher absolute values to qualify for safe resection; in other words, a 25 -yr-old patient with $20 \%$ ppo function for FEV1 has much more unhealthy lungs than a 70yr-old patient with a ppo value of $30 \%$, although in absolute values they both have $0.9 \mathrm{~L}$.

The current use of percent of predicted values has been shown to work well and, generally speaking, guidelines should suggest cut-off values which err on the side of safety. The trend to include more patients with marginal cardio-pulmonary functional reserves for resection will continue [4], but must be based on evidence.

\section{C.T. Bolliger*, A. Brunelli" ${ }^{*}$ and A. Charloux}

*Internal Medicine, University of Stellenbosch, Faculty of Health Sciences, Cape Town, South Africa, "Dept of Thoracic Surgery, Umberto I Regional Hospital, Ancona, Italy, and "Physiologie et Explorations Fonctionnelles, Hôpitaux Universitaires de Strasbourg, Strasbourg, France.
Correspondence: C.T. Bolliger, Internal Medicine, University of Stellenbosch, Faculty of Health Sciences; 7505 Tygerberg, Cape Town, South Africa, 75505. E-mail: ctb@sun.ac.za

Statement of Interest: None declared.

\section{REFERENCES}

1 Brunelli A, Charloux A, Bolliger CT, et al. ERS/ESTS clinical guidelines on fitness for radical therapy in lung cancer patients (surgery and chemo-radiotherapy). Eur Respir J 2009; 34: 17-41.

2 Bolliger CT, Perruchoud AP. Functional evaluation of the lung resection candidate. Eur Respir J 1998; 11: 198-212.

3 Quanjer PH, Tammeling GJ, Cotes JE, et al. Lung volumes and forced ventilator flows. Report Working Party Standardization of Lung Function Tests. European Community for Steel and Coal. Official Statement of the European Respiratory Society. Eur Respir J 1993; 6: Suppl. 16, S5-S40.

4 Bolliger CT. Functional reserve before lung resection. How low can we go? Respiration. 2009; 78: 20-22.

DOI: $10.1183 / 09031936.00187109$

\section{Assessment of linezolid efficacy and safety in MDR- and XDR-TB: an Indian perspective}

\section{To the Editors:}

We read with interest the analysis of the efficacy, tolerability and safety profile of linezolid in multidrug-resistant (MDR) and extensively drug-resistant (XDR) tuberculosis (TB) in the retrospective TBNET (Tuberculosis Network European Trials group) study by MigLIORI et al. [1]. Before this publication, scattered case reports and small case series have been the only source of data on the efficacy and safety of this drug in the treatment of MDR- and XDR-TB cases.

Linezolid is the first oxazolidinone to be developed and introduced in clinical use. In vitro studies have shown good activity against different species of mycobacteria, including resistant strains. The linezolid minimum inhibitory concentration to inhibit the growth of $90 \%$ of organisms for Mycobacterium tuberculosis is in the range of $1-2 \mathrm{mg} \cdot \mathrm{L}^{-1}$ [2]. However, clinical experience with the use of linezolid in the management of mycobacterial infection is still sparse.

The use of linezolid is especially relevant in a country like India, which bears the burden of a third of the world's MDRTB patients. The most recent, i.e. fourth, World Health Organization global resistance report, released in February 2008, estimated there were 110,132 cases of MDR-TB from India in 2006. This accounted for $20 \%$ of the world's MDR-TB burden. Between them, India and China accounted for $50 \%$ of the global MDR-TB burden [3].

Acquired drug resistance, not just to isoniazid and rifampicin, but also to other second-line drugs is also common in India and XDR-TB strains have been increasingly reported since the first report from India was published in 2007 [4]. Physicians increasingly need to fall back on newer (Group V) and experimental drugs in order to make up the minimum recommended number of active drugs (ideally four or five) to ensure a successful regime. Linezolid has been increasingly used in this role. It is relatively cheap, available off-patent and there are currently 10 generic preparations available in the Indian market. Little is known about its efficacy or toxicity in the Indian context.

We report our clinical experience with the use of linezolid in a cohort of 78 Indian MDR- and XDR-TB patients (36 males and 42 females) being treated at the chest outpatient department of a large private tertiary referral hospital in Mumbai (India). In this prospective, non-randomised study from 2000 to 2007, 18 out of the 78 patients received linezolid. Of these 18 patients, seven harboured XDR-TB and 11 were MDR-TB patients. The mean duration of therapy with the drug was as long as 20.6 months. All 18 patients received the drug only in a dose of $600 \mathrm{mg}$, once a day. Of these 18 cases, 11 patients were cured, four failed treatment and three were lost to follow-up. In our cohort, the use of linezolid was not associated with any difference in treatment outcome.

In comparison with the TBNET cohort (table 1), we noticed a higher incidence of major adverse reactions (61\%) in our patients. Chief among these was a severe peripheral neuropathy. 16 patients were affected by sensory-motor neuropathy. 